\title{
SOBRE LA EXPERIENCIA ÉTICA. DIRECCIONES DEL DISCURSO BIOÉTICO
}

\author{
Fernando Lolas Stepke ${ }^{1}$
}

Este número de Acta Bioethica agrupa artículos relacionados con aquella esfera de la experiencia profesional que no se adquiere en libros ni estudios empíricos sistemáticos. La que nace del contacto directo con las realidades es una forma inefable de experiencia, difícilmente explicable o enseñable, excepto por el ejemplo y la práctica.

No por azar la mayoría de los textos en este registro experiencial se refieren a la enfermería, práctica social y profesión que se caracteriza por el estrecho contacto de sus practicantes con personas. Estudios empíricos de hace varias décadas revelaron que en los hospitales, a medida que se agravan los enfermos, el tiempo de contacto de los médicos tiende a reducirse; el de las enfermeras y otros cuidadores tiende a incrementarse. También el de quienes ejercen labores religiosas y pastorales, según el clásico estudio de Petra Christian-Widmaier.

Por ello cabe destacar una vertiente esencial en el trabajo con los discursos éticos: la de la propia vivencia. Esta palabra, que los escritores de Revista de Occidente usaron para traducir la Erlebnis de Dilthey, refleja con notable exactitud aquello que solamente puede obtenerse por contacto directo con las realidades. Sin duda alguna, cuando se repite que el cuidado de la salud es un arte, se apela a esta dimensión estética de la praxis. Las "ciencias de acciones" o "praxiologías" no se valoran por productos o resultados visibles sino por la forma en que se ejercen las acciones. Es allí donde se puede apreciar la calidad y la calidez de los profesionales. Hacen bien su trabajo y en ello consiste la "eticidad" de su actuar. Pues el primer precepto ético de toda profesión es siempre técnico: haz bien lo que se espera de tu actuar.

En la tradición inaugurada por la neobioética estadounidense, con su énfasis en los algoritmos principialistas, se produce una falsa sensación de dominio técnico que obscurece esta dimensión personal de la experiencia. Muchos partícipes en comités de ética creen actuar científicamente si computan proporciones de autonomía, justicia, beneficencia y no maleficencia, y arriban a una suerte de expresión algebraica del conflicto moral. Esta sensación es grata, porque aparentemente resuelve problemas y ayuda a tomar decisiones, claves del proceso deliberativo. Pero raramente se pregunta por la experiencia interior de quienes participan en acciones o tienen responsabilidades. Falta para ello todo un armamentarium de métodos para sensibilizar a los observadores. Erróneamente, se piensa que estos métodos quedarían subsumidos bajo la ambigua fórmula de "métodos cualitativos". Estos, bajo la apariencia de diversidad, solo replican la racionalidad fundamental del acopio empírico de datos e informaciones.

Nos referimos, con estas observaciones, a la dimensión hermenéutica de la práctica bioética. Un modo de entender acciones y evaluarlas que puede llamarse "experiencial" e "interior", por oposición a aquellos procedimientos que intentar "objetivar" lo inefable. Una ética hermenéutica hace justicia, por cierto, a las aportaciones de las ciencias empíricas. Complementa la explicación de estas disciplinas con la comprensión subjetiva y, particularmente, con la interpretación. Este último paso "posiciona" o "sitúa" lo observado en un plexo de significaciones propio de una comunidad de hablantes. Inconscientemente, las "prácticas" y "residencias" habituales en las profesiones sanitarias pueden lograr algo de esta sensibilidad.

\footnotetext{
${ }^{1}$ Profesor Titular, Universidad de Chile. Secretario General, Asociación Mundial de Psiquiatría Social. Director, Acta Bioethica. Correspondencia: flolas@uchile.cl
} 
Aparte de las reflexiones que suscita el núcleo conceptual escogido para este número, hay en él novedosos trabajos misceláneos que agrupamos en la sección "Interfaces". Estas inter-faces son también lo que en alemán llaman Grenzgebiete, áreas limítrofes, de contacto con otras racionalidades y discursos. Sin duda alguna, el carácter híbrido del discurso bioético privilegia estas zonas y convierte a esta práctica disciplinar en un auténtico ejercicio de integración. No otro es el sentido que asignamos a su valor de "puente" entre personas, disciplinas, discursos e intereses sociales.

Completan el número un documento que recuerda una reunión en República Dominicana y una serie de recensiones. La experiencia ha demostrado que éstas son un valioso aporte para los lectores de lengua castellana y portuguesa. 